\title{
Using camera traps to study the age-sex structure and behaviour of crop-using elephants Loxodonta africana in Udzungwa Mountains National Park, Tanzania
}

\author{
Josephine Smit, Rocío A. Pozo, Jeremy J. Cusack \\ Katarzyna Nowak and Trevor Jones
}

\begin{abstract}
Crop losses to foraging elephants are one of the primary obstacles to the coexistence of elephants and people. Understanding whether some individuals in a population are more likely to forage on crops, and the temporal patterns of elephant visits to farms, is key to mitigating the negative impacts of elephants on farmers' livelihoods. We used camera traps to study the crop foraging behaviour of African elephants Loxodonta africana in farmland adjacent to the Udzungwa Mountains National Park in southern Tanzania during October 2010-August 2014. Camera traps placed on elephant trails into farmland detected elephants on 336 occasions during the study period. We identified individual elephants for 126 camera-trap detections. All were independent males, and we identified 48 unique bulls aged 10-29 years. Two-thirds of the bulls identified were detected only once by camera traps during the study period. Our findings are consistent with previous studies that found that adult males are more likely to adopt high-risk feeding behaviours such as crop foraging, although young males dispersing from maternal family units also consume crops in Udzungwa. We found a large number of occasional cropusers ( 32 of the 48 bulls identified) and a smaller number of repeat crop-users (16 of 48), suggesting that lethal control of crop-using elephants is unlikely to be an effective longterm strategy for reducing crop losses to elephants.
\end{abstract}

Keywords Crop foraging, HEC, human-elephant coexistence, PAC, problem animal control, Tanzania, Udzungwa Mountains

\footnotetext{
Josephine SMit* (Corresponding author), Katarzyna NowaK† and Trevor Jones Southern Tanzania Elephant Program, PO Box 2494, Iringa, Tanzania E-mail smitjosephine@gmail.com

Rocío A. Pozo Department of Zoology, University of Oxford, Oxford, UK

JEREMY J. CUSACK Biological and Environmental Sciences, University of Stirling, Stirling, UK

${ }^{*}$ Also at: Psychology, University of Stirling, Stirling, UK

$\dagger$ Also at: Zoology \& Entomology, University of the Free State, Qwaqwa Campus, Phuthaditjhaba, South Africa

Received 14 October 2016. Revision requested 21 November 2016. Accepted 23 February 2017. First published online 28 June 2017.
}

Supplementary material for this article can be found at https://doi.org/10.1017/So030605317000345

\section{Introduction}

The population decline of African elephants Loxodonta 1 africana, categorized as Vulnerable on the IUCN Red List (Blanc, 2008), is one of the most pressing conservation issues currently facing sub-Saharan Africa (Maisels et al., 2013; Wittemyer et al., 2014; Wasser et al., 2015; Chase et al., 2016). Another challenge for elephant conservation in the long term is coexistence with people, in particular where elephants consume or damage crops (Hoare, 2015). Given their large ranges and long-distance movements (Graham et al., 2009), elephants spend considerable time outside protected areas (Blanc et al., 2007; van Aarde \& Jackson, 2007; Kikoti, 2009), where they are more likely to share and compete for space and resources with people. The impacts of elephants outside protected areas include loss of crops and reduced yields, damage to property, death of livestock, and injury (and in some cases death) of people (Thouless, 1994; Ngure, 1995; Kangwana, 1996; Lahm, 1996). These impacts on people and their livelihoods can lead to retaliatory and legal killing of elephants under Problem Animal Control policies (Hoare, 2000, 2015). In this context, understanding which elephants in a population are more likely to forage on crops, and investigating temporal patterns in crop foraging behaviour are integral to developing effective strategies for reducing crop losses to elephants (Naughton-Treves, 1998).

Previous studies have highlighted a male bias in elephant crop foraging behaviour (Osborn, 1998; Hoare, 1999; Sitati et al., 2003; Graham et al., 2010; Chiyo et al., 2011, 2012; Ekanayaka et al., 2011). Crop foraging is a high-risk, highgain strategy for male elephants to maximize their nutrient intake while minimizing the time spent and distance travelled while foraging (Sukumar \& Gadgil, 1988; Chiyo \& Cochrane, 2005). Crop foraging has also been observed in males of other polygamous species, including at least nine species of African primates (Trivers, 1985; Davenport et al., 2006; Wallace \& Hill, 2012). In contrast, females may not exhibit this behaviour as often as males because 
of the potential risk to dependent offspring in agricultural landscapes (Sukumar \& Gadgil, 1988). This is not always the case, however, as studies in south-eastern Tanzania and around Tsavo National Park, Kenya, found that mixed groups consisting of bulls, females and calves were responsible for the majority of crop loss incidents (Smith \& Kasiki, 2000; Malima et al., 2005). However, age and sex data from enumerator-based studies may be unreliable, as they commonly rely on interviews with farmers, who are usually not formally trained in sexing and ageing elephants (Smith \& Kasiki, 200o).

Repeat or habitual crop use by African elephants has been reported previously (Hoare, 2001; Chiyo \& Cochrane, 2005; Chiyo et al., 2011, 2012). A study in Amboseli, Kenya, found considerable variation in crop use among individuals (Chiyo et al., 2011), with a small number of bulls feeding on crops relatively frequently, and others sporadically. Bulls may also acquire crop foraging behaviour through social learning, and therefore the structure of male association networks may influence the tendency for crop use in bulls and drive differences in crop foraging behaviour between individuals (Chiyo et al., 2012).

Elephant crop foraging behaviour is difficult to study because incidents usually occur at night (Gunn et al., 2014), and thus direct observation in the field is often risky and hampered by poor visibility. Previous studies have employed indirect methods to assess the sex and age structure of crop users; for example, estimating elephant age from dung size and footprint diameter (Chiyo \& Cochrane, 2005; Morrison et al., 2005). Others have studied elephant crop use at the individual level using genetic data collected from elephant dung (Chiyo et al., 2011). Camera traps have been widely implemented to identify individuals (Karanth \& Nichols, 1998; Silver et al., 2004) and investigate behaviour that could be challenging to study using direct observations (Griffiths \& van Schaik, 1993); however, they have not previously been used to study crop foraging behaviour in elephants.

We used camera traps to investigate patterns of crop use and to establish the number, sex and age structure of crop-using elephants along the boundary between Udzungwa Mountains National Park and adjacent farmland in southcentral Tanzania during October 2010-August 2014. We discuss the implications of our results in the context of current policies for managing crop losses to elephants at our study site in Tanzania, and more generally across Africa where elephants and people co-occur.

\section{Study area}

The study site is in Njokomoni, a small area of farmland (c. $2.5 \mathrm{~km}^{2}$ ) directly adjacent to the Udzungwa Mountains National Park in south-central Tanzania. The Udzungwa

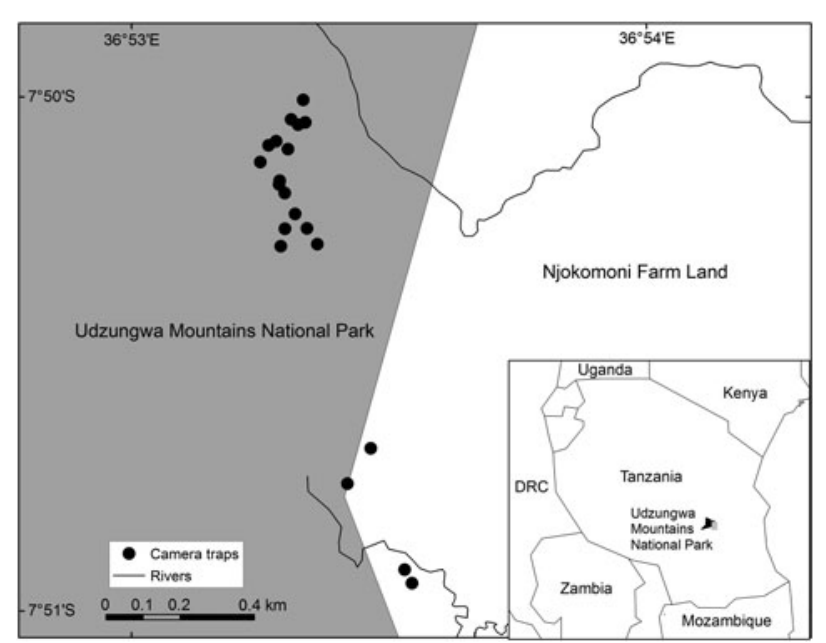

FIG. 1 The study area in Udzungwa Mountains National Park and the adjacent farmland of the Njokomoni area, Tanzania.

Mountains encompass the largest and biologically richest forest blocks of the Eastern Arc Mountains (Burgess et al., 2007), and are home to a relatively young, recovering population of forest-using savannah elephants (Nowak et al., 2009). After heavy poaching between the 1960 s and 1980 s led to the near extinction of elephants in the Udzungwa Mountains, this population, presumed to have taken refuge at high elevations (Jones \& Nowak, 2015), began to recover following the gazetting of the National Park in 1992 (Joram, 2011).

The Njokomoni area is farmed by people from the villages known as Mang'ula A and Mang'ula B, both located along the east-facing escarpment of the Udzungwa Mountains (Fig. 1). The vegetation along the eastern side of the Park comprises lowland rainforest and miombo woodland, which extend to the Park boundary. Crop losses to elephants in the area emerged as a regular occurrence in 2008 (Joram, 2011) and appeared to be related to the blockage of elephant movements associated with the loss of wildlife corridors between the Udzungwa Mountains and the Selous Game Reserve (Jones et al., 2012).

The Njokomoni farmland comprises $>120$ farms of $0.25-2$ ha. Over 30 crops are cultivated in a mixed intercropping system (Joram, 2011). The wet season spans NovemberMay, and the dry season June-October (Lovett \& Wasser, 1993). Farming activity occurs year-round, with rain-fed farming during the wet season and irrigated farming during the dry season, facilitated by perennial streams. Crop losses to elephants occur throughout the year but are generally more frequent in the dry season, peaking in September when the irrigated maize crop matures. A 2010-2011 survey of six adjacent villages along the eastern boundary of the Park identified Njokomoni as a hotspot of elephant crop use, as $>75 \%$ of verified reports of crop losses came from farmers in Njokomoni (Joram, 2011). The major reason for high levels of elephant activity in this area is the lack 
of a buffer zone between the Park and adjacent farms (Joram, 2011).

\section{Methods}

\section{Camera trapping}

During October 2010-August 2014 a total of 23 camera-trap sites were monitored along a c. $1 \mathrm{~km}$ stretch of the eastern boundary of Udzungwa Mountains National Park. Effort and coverage were variable over this period, with 1-10 camera traps active each night during October 2010-April 2012, 1-3 during August 2012-January 2013, and 10 during July 2013-August 2014 (Supplementary Table S1). Heat and motion camera traps (Cuddeback Capture, Cuddeback, De Pere, USA) were placed along known elephant pathways to and from farms, and were shifted according to elephant activity, as indicated by the presence of elephant dung and tracks. Given the limited number of cameras available, only one camera trap was placed per trail. To obtain suitable portrait photographs for individual identification, camera traps were mounted on trees at a height of $3 \mathrm{~m}$ and oriented downwards to capture the head, pinnae and tusks of passing elephants. Camera traps were programmed to take colour photographs with an incandescent flash, and the trigger interval was set to $30 \mathrm{~s}$ (the minimum possible for the model). Batteries were replaced and SD cards downloaded every 2 weeks.

A database of all camera-trap images of elephants was created, which included the site, date and time of capture, and the direction of elephant movement (into the farmland area or back into the Park). In addition, images were categorized according to whether or not they were suitable for individual identification. For those images that were deemed suitable, the elephant's sex and, when possible, age were determined, and individuals were identified based on unique characteristics of their pinnae and tusks (Moss, 1996). The sexing and ageing of elephants was carried out by JS following training at the Amboseli Elephant Research Project, Kenya, on elephants of known age.

\section{Monitoring crop losses to elephants}

Monitoring of crop losses to elephants in the focal area was carried out following a modified protocol developed by the African Elephant Specialist Group of IUCN (Parker et al., 2007). Two local enumerators employed by the Southern Tanzania Elephant Program responded to calls from farmers reporting crop loss incidents, and surveyed farms within the study area 6 days per week for additional unreported incidents. They recorded the date and location of the incident, the types of crops and trees eaten or trampled, and the size of the area affected (Joram, 2011).

\section{Data analysis}

To account for inconsistent camera-trapping effort, we considered two time periods for analysis: the entire study period and the final year of monitoring (July 2013-August 2014). We ran a temporal analysis comparing the timing of camera-trap captures of elephants travelling into or out of the farmland area. More specifically, we used a non-parametric Kolmogorov-Smirnov test to determine whether the distributions of timings of captures into and out of farmland were significantly different. To do this, we used data collected over the entire study period, as temporal activity at the scale of a single night is unlikely to be affected by inconsistent cameratrap effort. Image time stamps were grouped into 24 onehour bins (o-23), resulting in a frequency distribution spread over 24 hours.

We also tested for a significant association between the detection of an elephant by any of the camera traps in operation (absence $=0$, presence $=1$ ) and the recording of a crop loss incident in the Njokomoni farmland on the following day by enumerators (absence $=0$, presence $=1$ ), using data collected during July 2013-August 2014. We arranged corresponding frequencies in a $2 \times 2$ contingency table and performed a Pearson's $\chi^{2}$ test of independence to investigate whether observed frequencies were more or less than those expected by chance. We used data from the final year of monitoring, as camera-trap effort during this period was constant (10 cameras operating every night). In addition, to assess whether monthly patterns of camera-trapping events served as a good indicator of crop loss incidence, we correlated the proportion of days in the month for which at least one elephant photograph was obtained and the proportion of days for which a crop loss incident had been recorded by the enumerators.

In addition, we estimated the minimum number of elephants known to use the forest/farm boundary area over both the entire study period and the final year based on individuals identified from camera-trap images (for photographs of two bulls detected multiple times, see Supplementary Plate $\mathrm{S}_{1}$ ). We also assessed the number of nights that individual bulls had been detected by camera traps, and used this as an indicator of the relative likelihood of a bull visiting the Njokomoni farmland area. We repeated this assessment using a subset of our data for which camera detections of elephants were positively associated with crop loss incidents (Supplementary Fig. S1).

We investigated the sex and age structure of individuals identified over the 4-year study period. We grouped elephants identified in camera-trap photographs into four age categories (Moss, 1996): 10-14, 15-19, 20-24 and 25-29 years (we did not observe any individuals $>30$ years old). As our cameras detected only male elephants, we relied primarily on head size and shape for ageing because these features change noticeably with age and are clearly visible 


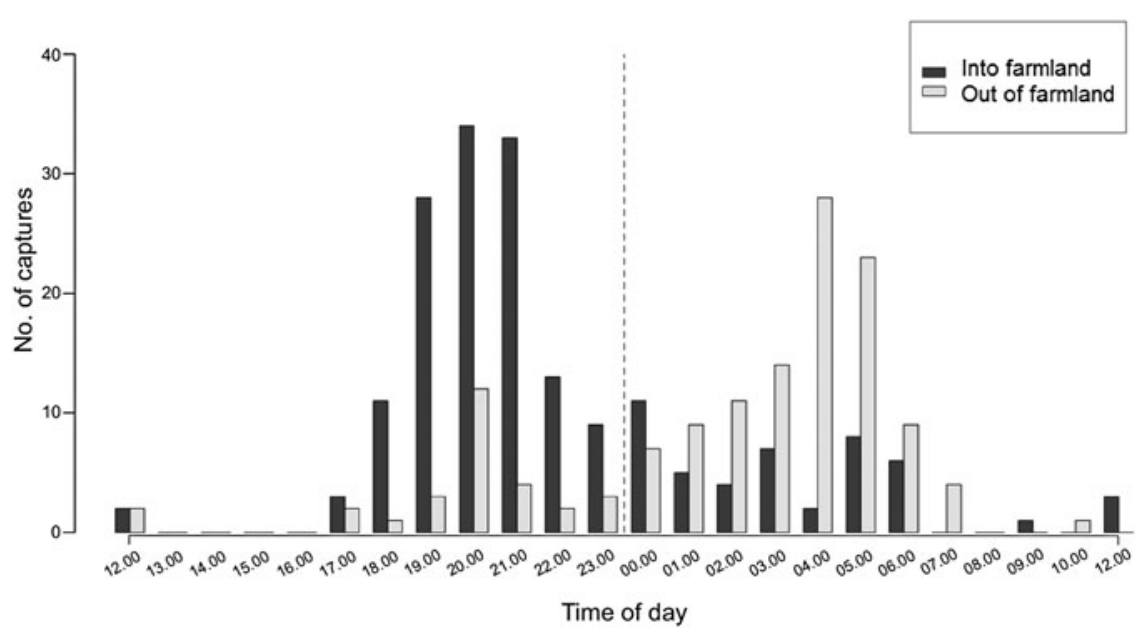

FIG. 2 Temporal pattern of elephant Loxodonta africana detections at camera traps placed along the eastern border of Udzungwa Mountains National Park (Fig. 1). on camera-trap photographs. The head of a male elephant increases in size with age, and takes on a pronounced hourglass shape around the age of 25 (Moss, 1996). For full-body photographs we also used height and body size for ageing. For images of bulls representative of the four age classes used, see Supplementary Plate S2. $R$ v. 3.o.1 (R Development Core Team, 2014) was used for all statistical analysis.

\section{Results}

We obtained 443 photographs of elephants over 5,314 trapnights, representing 336 independent events. We defined an event as the capture of a unique elephant at a unique date and time, as this best represented one visit by a single elephant. In cases where an event could not be defined by distinguishing between individual elephants, an arbitrary time threshold of 5 minutes between separate events was assumed. Elephants were photographed travelling into the farmland predominantly during 18.00-00.00 (median $=19.00)$ and back into the Park during 00.00-07.00 (median =04.00) $\quad($ Kolmogorov Smirnov test: $\mathrm{D}=0.541, \mathrm{P}<0.001$; Fig. 2 ). We found a similar pattern in elephant movements into and out of farmland when we used a subset of the data for which camera detections of elephants were associated with crop loss incidents (Supplementary Fig. S1). During the final year of the study we found that camera-trap data and crop loss incidents as recorded by enumerators co-occurred more than expected by chance $\left(\mathrm{n}=39, \chi^{2}=13.6, \mathrm{df}=1, \mathrm{P}<0.001\right)$. Nonetheless there was still a high number of instances when crop losses were reported but no elephants were photographed $(n=98)$, and when cameras detected elephants but no crop losses were recorded $(n=118)$. We also found a positive, albeit non-significant, correlation between the proportion of days in the month for which we obtained camera-trap images of elephants and that for which crop losses were reported $\left(r^{2}=0.407, \mathrm{df}=10, \mathrm{P}=0.19\right.$; Fig. 3 ).

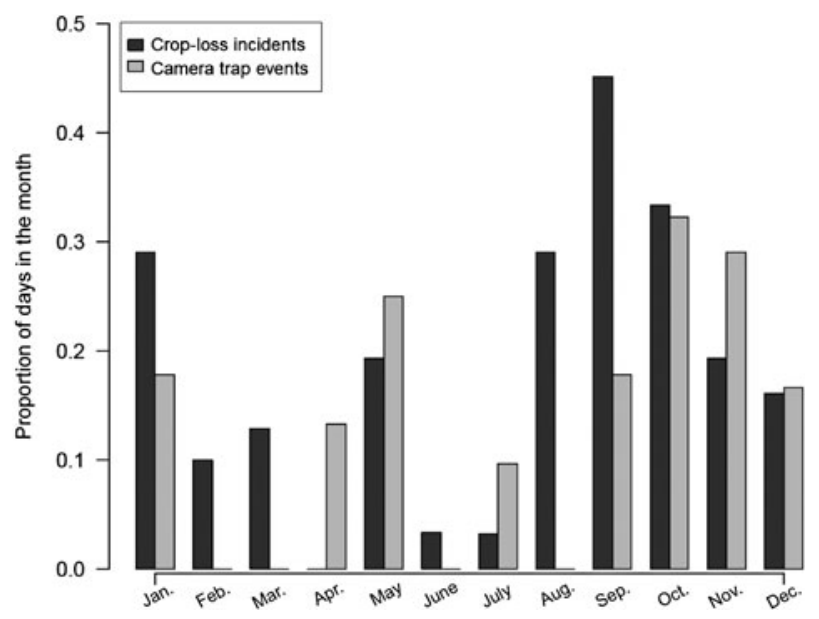

Fig. 3 Proportion of days in the month for which crop loss incidents were reported, and on which elephants were detected by camera traps along the eastern border of Udzungwa Mountains National Park (Fig. 1).

We were able to identify individual elephants in $37 \%$ $(n=126)$ of the 336 camera-trap events. All of the 48 individuals identified were males (Fig. 4). Most of the bulls identified were detected only once by camera traps during the study period (66.7\%; Fig. 5), and this pattern was also found during the final year of the study, when cameratrapping effort was constant (70.6\%; Fig. 5). A skew towards single detections was also found when we considered only those camera detections of bulls associated with crop loss incidents (Supplementary Fig. S2).

Sixteen individuals were photographed multiple times during the study period (Fig. 5), with one individual detected $>30$ times. Five of the 17 bulls identified in the final year of the study were captured on camera multiple times (Fig. 5). The majority of the 48 bulls identified from camera-trap images during the study period were 25-29 years old (Fig. 6). Bulls who were detected multiple times were also primarily of this age group, followed by younger 


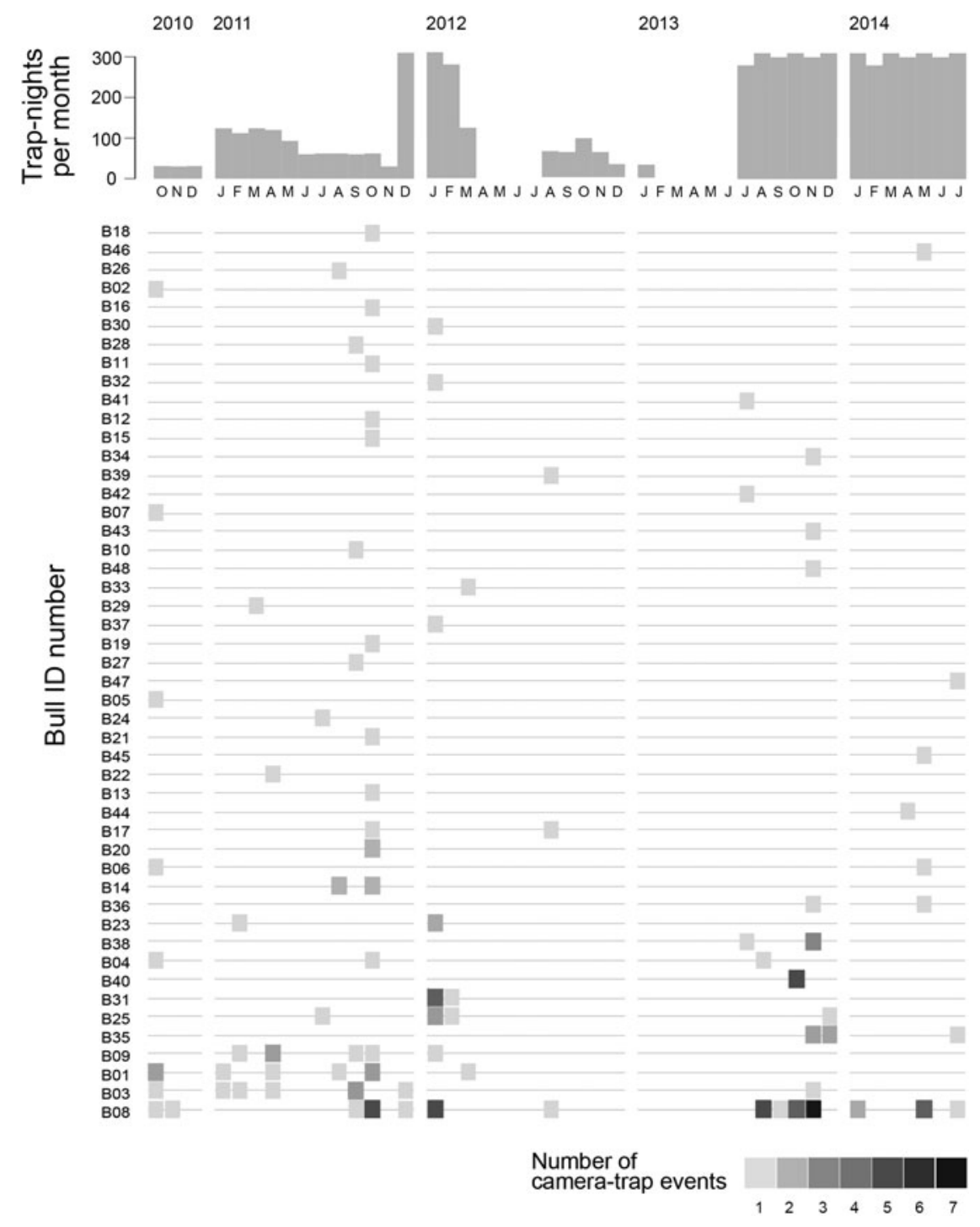

FIg. 4 Camera-trap detection rates for 48 identified bull elephants, in ascending order (from top to bottom) of frequency of detection during the study period (October 2010-August 2014). The histogram shows the sampling effort in trap-nights per month. bulls aged 10-14 and 15-19 years. The time between successive detections of individual bulls was highly variable (range 0-681 days, median 13.5 days), probably largely because of the inconsistency in camera-trap effort (although we cannot exclude the possibility that some of the bulls had breaks in visits to the study area). However, a conservative estimate is that $24 \%$ of re-captures occurred on 2 consecutive days, and $43 \%$ of re-captures occurred within 7 days.

\section{Discussion}

In a test of camera-trapping as a tool to investigate the behaviour, number, and age and sex structure of crop-using elephants along the boundary between Udzungwa Mountains National Park and adjacent farmland in southcentral Tanzania, we found a distinct pattern of elephant activity, with elephants entering farmland at night and returning to the Park early in the morning, along regular trails.
This is consistent with previous findings of avoidance of farmers by elephants, and a propensity for nocturnal crop foraging behaviour (Smith \& Kasiki, 200o; Graham et al., 2010; Chiyo et al., 2012; Gunn et al., 2014; Wilson et al., 2015). The evidence that elephants use these trails for the purpose of entering farms and consuming crops is strengthened by the significant pattern of co-occurrence between camera-trap records of elephants, and crop-loss incidents recorded by local enumerators.

However, we did not find a significant temporal correlation between recorded crop losses and camera detections of elephants. This could be because not every crop foraging attempt by a bull was successful (i.e. bulls photographed while entering farmland did not always consume crops, as they may have encountered risks such as the presence of farmers, fire or dogs). This suggests that the frequency of elephant visits to farmland as detected by camera traps, and the extent of crop damage recorded by enumerators, may be independent measures of elephant crop foraging 

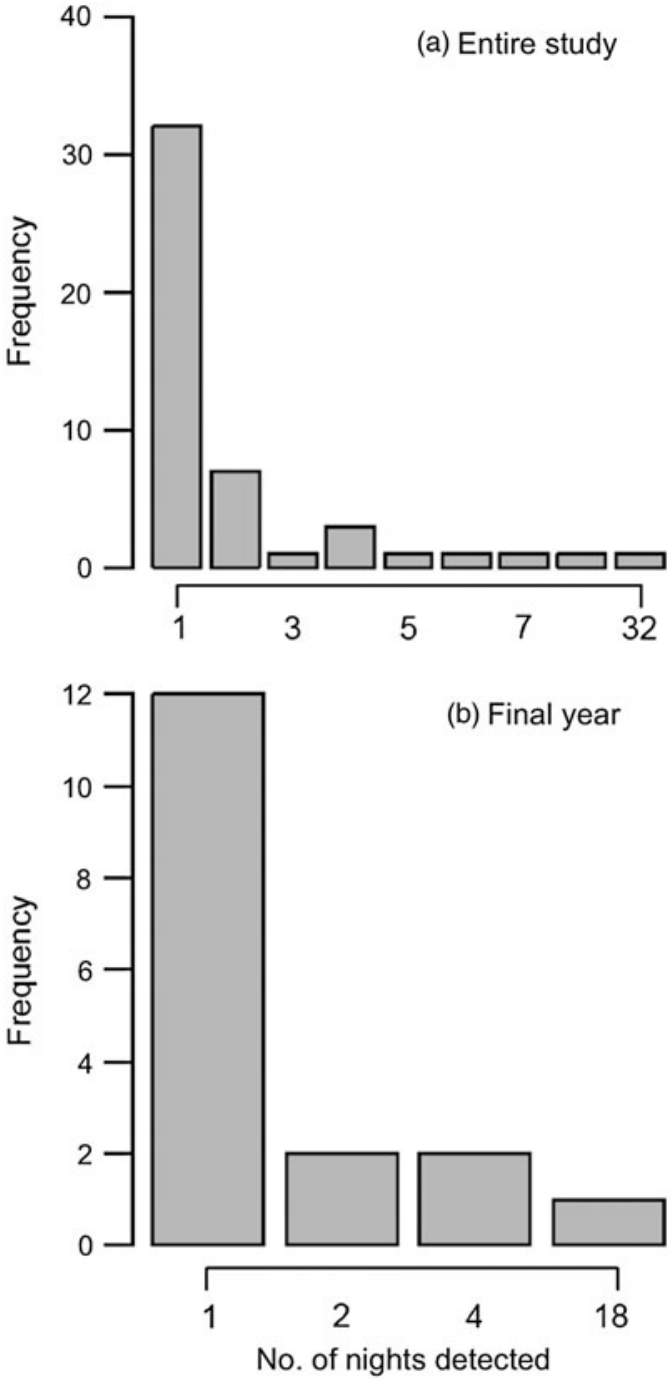

FIG. 5 Frequency distributions of the number of nights on which identified bulls were detected by camera traps (a) for the entire study period, and (b) for the final year only.

behaviour. Additionally, it may be that bulls occasionally used routes to farmland that were not sampled by our camera traps. Therefore, camera trapping may not be suitable for studying temporal patterns in crop losses to elephants. Nevertheless, we consider camera trapping and enumeration of crop losses to be complementary indices with the potential to improve the reliability of data on elephant crop use if used jointly, especially in areas where elephants use well-established trails into farmland (Von Gerhardt et al., 2014).

Using standard ways of identifying individual elephants on the basis of tusks and ears, we identified a minimum of 48 bulls in our study area during the 4-year study period. However, reliable individual identification was possible from only c. $37 \%$ of the camera-trap detections. Future studies could increase the success rate of identification by increasing the number of camera traps active per night, and
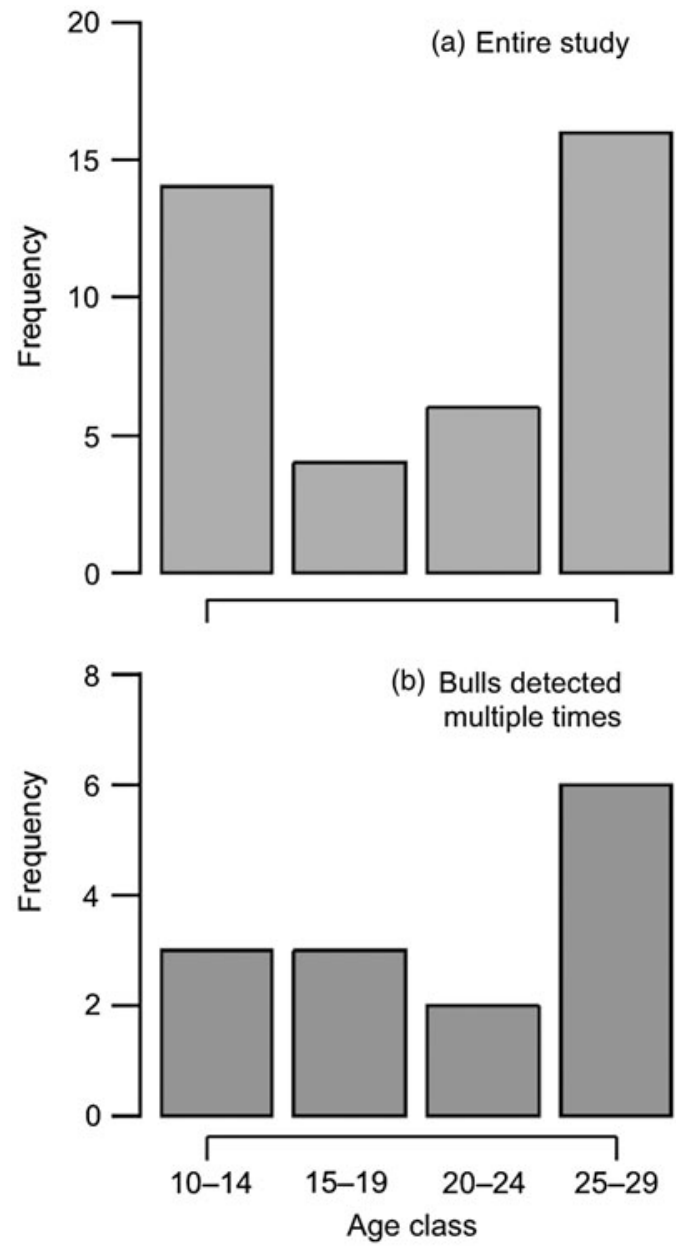

FIG. 6 Age structure of (a) 40 of the 48 bull elephants identified over the entire study period, and (b) 14 of the 16 bull elephants who were detected multiple times during the study period.

by using two opposite-facing camera traps per trail, as is done in studies of large felids (Kelly et al., 2008; Harihar et al., 2010).

Most of the bulls identified were aged $20-29$ years (55\%), followed by younger bulls aged 10-14 (34\%) and 15-19 (11\%) years, which raises the possibility that older bulls are leading younger bulls into farms, or that they comprise a larger portion of the boundary-visiting population. The age structure of crop-using bulls in Udzungwa is consistent with previous studies carried out in Kibale, Uganda (Chiyo \& Cochrane, 2005) and Amboseli, Kenya (Chiyo et al., 2012) (Table 1). Our results indicate that crop use in Udzungwa could be an example of a high-risk, high-gain foraging strategy linked to male life-history milestones, including dispersal from the maternal family unit and the initiation of reproduction, with associated increases in energetic demands (Chiyo et al., 2012).

In Udzungwa, as in Kibale, the youngest bulls involved in crop foraging were 10-14 years old, suggesting that crop use may be initiated during male dispersal (Chiyo \& Cochrane, 
TABLE 1 Age structure of crop-using bull elephants Loxodonta africana at three sites in East Africa: Udzungwa Mountains National Park, Tanzania (this study), Kibale National Park, Uganda (Chiyo \& Cochrane, 2005), and Amboseli National Park, Kenya (Chiyo et al., 2012).

\begin{tabular}{llll}
\hline Age (years) & $\begin{array}{l}\text { Udzungwa } \\
(\% \text { population })\end{array}$ & $\begin{array}{l}\text { Kibale } \\
(\% \text { dung piles })\end{array}$ & $\begin{array}{l}\text { Amboseli } \\
(\% \text { population })\end{array}$ \\
\hline $5-9$ & 0 & 6 & 0 \\
$10-14$ & 34 & 22 & 0 \\
$15-19$ & 11 & 32 & 7 \\
$20-24$ & 15 & 27 & \\
$25-29$ & 40 & $13(>25$ years $)$ & $50(20-30$ years $)$ \\
$>30$ & 0 & & 43 \\
\hline
\end{tabular}

2005). This is a time when males leave their natal groups and search for new feeding areas, and show greater exploratory and risk-taking behaviour, thus increasing their chances of coming into contact with crops (Chiyo \& Cochrane, 2005). In Amboseli $>40 \%$ of crop-using bulls were $>30$ years old (Chiyo et al., 2012), whereas we did not identify any bulls over the age of 30 in Udzungwa. This probably reflects the history of poaching in Udzungwa, which typically leaves populations with few older bulls (Mondol et al., 2014) and a population structure biased towards younger age classes (Poole, 1989; Nowak et al., 2009).

Our study finds considerable variation in crop foraging behaviour between individual bulls, with camera traps detecting some bulls more frequently than others. Over two-thirds of the 48 bulls identified were detected by camera traps only once during the study period, and the same pattern was evident for the 17 bulls identified in the final year of the study. This suggests that a large number of bulls are occasional crop-users. Sixteen bulls were detected multiple times (2-32) on camera during the study period, suggesting these individuals may be repeat crop-users. There was considerable variation in detection rates of repeat crop-users, with one bull detected four times more frequently than any other repeat crop-user. These are likely to be conservative numbers, and we acknowledge that many elephants may have gone undetected because of the small number of cameras available, the large proportion of photographs from which individual identification was not possible, and the likelihood of cameras failing to record elephant visits.

Nevertheless, we highlight a large pool of occasional crop-users and a few repeat crop-users, a pattern also detected using genetic data in Amboseli, Kenya (Chiyo et al., 2011). Repeat crop use by certain individuals was also observed in a study of radio-tracked bull elephants in Muzarabani District in Zimbabwe (Hoare, 2001), and via the presence of crop remains in elephant dung on farms bordering Kibale National Park (Chiyo \& Cochrane, 2005). Repeat crop use seems to be more common among older males in Udzungwa, where almost half of the repeat crop-users were bulls aged 25-29 years. Similarly, studies in Kibale and Amboseli found a positive correlation between age of the bull and the likelihood of repeat crop use (Chiyo \& Cochrane, 2005; Chiyo et al., 2011).

The time between successive camera captures of bulls that were detected multiple times was highly variable (range 0-681 days, median 13.5 days). Although inconsistent camera-trapping effort complicates the picture, it is possible that some of these potentially repeat crop-users had breaks in visits to the study area. For three of the bulls, the time between successive detections was a year or longer. These results bear some similarity to visitation patterns of forest elephants in the Dzanga Bai, in Dzanga-Ndoki National Park, Central African Republic (Turkalo et al., 2013). Long-term monitoring of the Dzanga Bai indicated that individual visitation patterns were highly variable, especially among males, some of whom were absent for years at a time (Turkalo et al., 2013).

Our study has implications for strategies to mitigate crop losses to elephants, particularly the legal killing of animals considered to be pests under Problem Animal Control policies, which have been applied across elephant range in Africa and Asia in an attempt to reduce crop losses to elephants (Hoare, 2001; Puyravaud et al., 2016). However, the persistence of crop foraging behaviour in areas where Problem Animal Control has been implemented in the long term, such as in the Selous Game Reserve in Tanzania and Muzarabani District in Zimbabwe, has led to concerns regarding its effectiveness and motivation (Malima et al., 2005; Hoare, 2015). Although we found evidence of repeat crop use by elephants, the much larger pool of occasional crop-users supports the argument against the killing of elephants as an effective crop-loss reduction method in Udzungwa. Furthermore, the finding that a large number of bulls use a small area of farmland (a hotspot of elephant crop use; Joram, 2011) suggests that high levels of crop loss at such hotspots do not result from the activity of a few habitual crop-users. Lethal elimination of crop-users carries the risk of misidentifying individual elephants, and can also be used as justification for elephant poaching or ivory accumulation under the pretext of Problem Animal Control (Masunzu et al., 1998; Malima et al., 2005). Removal of habitual crop-users may also create a gap or opportunity for new habitual crop-users to emerge (Hoare, 2015), and therefore our findings are in agreement with previous work questioning the effectiveness of killing elephants under Problem Animal Control policies for crop-loss mitigation.

\section{Acknowledgements}

We thank the Tanzania Wildlife Research Institute and the Tanzania Commission for Science and Technology for permission to conduct this research. We thank Udzungwa Mountains National Park staff for their support, in particular 
P. Joram. This work would not have been possible without our Tanzanian colleagues and enumerators: A. Mndeme, N. Kaluse and J. Kidibule. We thank WWF Tanzania for lending us their camera traps; the U.S. Fish and Wildlife Service African Elephant Conservation Fund, Idea Wild and Yale University's Summer Environmental Fellowship for funding; D. Lloyd-Jones for producing Fig. 4; F. Lihwa for producing Fig. 1; S.C. Stearns, C. Beale, T. Coulson and P.C. Lee for their advice and guidance; and two anonymous reviewers for their comments.

\section{Author contributions}

TJ, KN, and JS conceived the study and collected and processed data. RP, JC, and JS conducted data analysis and produced figures. All authors contributed to writing the article.

\section{References}

BLANC, J.J. (2008) Loxodonta africana. In The IUCN Red List of Threatened Species 2008: e.T12392A3339343. Http://dx.doi.org/10. 2305/IUCN.UK.2008.RLTS.T12392A3339343.en [accessed 15 March 2017].

Blanc, J.J., Barnes, R.F.W., Craig, G.C., Dublin, H.T., Thouless, C.R., Douglas-Hamilton, I. \& Hart, J.A. (2007) African Elephant Status Report 2007: An Update from the African Elephant Database. Occasional Paper Series of the IUCN Species Survival Commission, No. 33. IUCN/SSC African Elephant Specialist Group. IUCN, Gland, Switzerland.

Burgess, N.D., Butynski, T.M., Cordeiro, N.J., Doggart, N.H., FJeldSÅ, J., Howell, K.M. et al. (2007) The biological importance of the Eastern Arc Mountains of Tanzania and Kenya. Biological Conservation, 134, 209-231.

Chase, M.J., Schlossberg, S., Griffin, C.R., Bouché, P.J.C., Djene, S.W., ElKan, P.W. et al. (2016) Continent-wide survey reveals massive decline in African savannah elephants. PeerJ, 4, e2354.

Chiyo, P.I. \& Cochrane, E.P. (2005) Population structure and behaviour of crop-raiding elephants in Kibale National Park, Uganda. African Journal of Ecology, 43, 233-241.

Chiyo, P.I., Moss, C.J., Archie, E.A., Hollister-Smith, J.A. \& Alberts, S.C. (2011) Using molecular and observational techniques to estimate the number and raiding patterns of crop-raiding elephants. Journal of Applied Ecology, 48, 788-796.

Chiyo, P.I., Moss, C.J. \& Alberts, S.C. (2012) The influence of life history milestones and association networks on crop-raiding behavior in male African elephants. PLoS ONE, 7(2), e31382.

Davenport, T.R., Stanley, W.T., Sargis, E.J., De Luca, D.W., Mpunga, N.E., Machaga, S.J. \& Olson, L.E. (2006) A new genus of African monkey, Rungwecebus: morphology, ecology, and molecular phylogenetics. Science, 312, 1378-1381.

Ekanayaka, S.K.K., Campos-Arceiz, A., Rupasinghe, M., Pastorini, J. \& Fernando, P. (2011) Patterns of crop raiding by Asian elephants in a human-dominated landscape in southeastern Sri Lanka. Gajah, 34, 20-25.

Graham, M.D., Douglas-Hamilton, I., Adams, W.M. \& Lee, P.C. (2009) The movement of African elephants in a human-dominated land-use mosaic. Animal Conservation, 12, 445-455.

Graham, M.D., Notter, B., Adams, W.M., Lee, P.C. \& Ochieng, T. N. (2010) Patterns of crop-raiding by elephants, Loxodonta africana, in Laikipia, Kenya, and the management of human-elephant conflict. Systematics and Biodiversity, 8, 435-445.

Griffiths, M. \& van SCHAik, C.P. (1993) Camera trapping: a new tool for the study of elusive rainforest animals. Tropical Biodiversity, $1,131-135$.

Gunn, J., Hawkins, D., Barnes, R.F.W., Mofulu, F., Grant, R.A. \& Norton, G.W. (2014) The influence of lunar cycles on crop-raiding elephants; evidence for risk avoidance. African Journal of Ecology, 52, 129-137.

Harihar, A., Ghosh, M., Fernandes, M., Pandav, B. \& Goyal, S. P. (2010) Use of photographic capture-recapture sampling to estimate density of striped hyena (Hyaena hyaena): implications for conservation. Mammalia, 74, 83-87.

HoAre, R.E. (1999) Determinants of human-elephant conflict in a land use mosaic. Journal of Applied Ecology, 36, 689-70o.

HoARE, R.E. (2000) Humans and elephants in conflict: the outlook for co-existence. Oryx, 34, 34-38.

Hoare, R.E. (2001) Management implications of new research on problem elephants. Pachyderm, 30, 44-48.

HoARE, R.E. (2015) Lessons from 20 years of human-elephant conflict mitigation in Africa. Human Dimensions of Wildlife, 20, 289-295.

Jones, T., Bamford, A.J., Ferrol-Schulte, D., Hieronimo, P., McWilliam, N. \& Rovero, F. (2012) Vanishing wildlife corridors and options for restoration: a case study from Tanzania. Tropical Conservation Science, 5, 463-474.

Jones, T. \& NowaK, K. (2015) Elephant hideout: an unusual population of mountain-climbing elephants. In The Udzungwa Mountains: The Story of a Unique Rainforest in Eastern Africa (eds F. Rovero, N. Scharff, S. Brogger-Jensen \& F. Pagh Jensen), pp. 128-135. The Natural History Museum of Denmark, Copenhagen, Denmark.

JoRAm, P. (2011) Employing novel approaches in the study of humanelephant conflicts along the eastern boundary of Udzungwa Mountains National Park, Tanzania. MSc thesis. Université de Poitiers, Poitiers, France.

KangWanA, K. (1996) Assessing the impact of human-elephant interactions. In Studying Elephants (ed. K. Kangwana), pp. 138-147. African Wildlife Foundation, Nairobi, Kenya.

Karanth, K.U. \& Nichols, J.D. (1998) Estimation of tiger densities in India using photographic captures and recaptures. Ecology, 79, 2852-2862.

Kelly, M.J., Noss, A.J., Di Bitetti, M.S., Maffei, L., Arispe, R.L., Paviolo, A. et al. (2008) Estimating puma densities from camera trapping across three study sites: Bolivia, Argentina, and Belize. Journal of Mammalogy, 89, 408-418.

Кікоті, A.P. (2009) Seasonal home range sizes, transboundary movements and conservation of elephants in northern Tanzania. $\mathrm{PhD}$ thesis. University of Massachusetts, Amherst, USA.

LAHM, S.A. (1996) A nationwide survey of crop-raiding by elephants and other species in Gabon. Pachyderm, 21, 69-77.

LovetT, J.C. \& WASSer, S.K. (1993) Biogeography and Ecology of the Rain Forests of Eastern Africa. Cambridge University Press, Cambridge, UK.

Maisels, F., Strindberg, S., Blake, S., Wittemyer, G., Hart, J., Williamson, E.A. et al. (2013) Devastating decline of forest elephants in Central Africa. PLoS ONE, 8(3), e59469.

Malima, C., Hoare, R.E. \& BlanC, J.J. (2005) Systematic recording of human-elephant conflict: a case study in south-eastern Tanzania. Pachyderm, 38, 29-38.

Masunzu, C., Ludwig, S. \& Baldus, R.D. (1998) Assessment of crop damage and application of non-lethal deterrents for crop protection east of the Selous Game Reserve. Tanzania Wildlife Discussion Paper 24. 
Mondol, S., Mailand, C.R. \& Wasser, S.K. (2014) Male biased sex ratio of poached elephants is negatively related to poaching intensity over time. Conservation Genetics, 15, 1259-1263.

Morrison, T.A., Chiyo, P.I., Moss, C.J. \& Alberts, S.C. (2005) Measures of dung bolus size for known-age African elephants (Loxodonta africana): implications for age estimation. Journal of Zoology, 266, 89-94.

Moss, C.J. (1996) Getting to know a population. In Studying Elephants (ed. K. Kangwana), pp. 58-74. African Wildlife Foundation, Nairobi, Kenya.

Naughton-Treves, L. (1998) Predicting patterns of crop damage by wildlife around Kibale National Park, Uganda. Conservation Biology, 12, 156-168.

Ngure, N. (1995) People-elephant conflict management in Tsavo, Kenya. Pachyderm, 19, 20-25.

Nowak, K., Jones, T. \& Lee, P.C. (2009) Using dung bolus diameter for age estimation in an unstudied elephant population in Udzungwa Mountains, Tanzania. Pachyderm, 46, 47-52.

Osborn, F.V. (1998) The ecology of crop-raiding elephants in Zimbabwe. PhD thesis. University of Cambridge, Cambridge, UK.

Parker, G.E., Osborn, F.V., Hoare, R.E. \& Niskanen, L.S. (eds) (2007) Human-Elephant Conflict Mitigation: A Training Manual for Community-Based Approaches in Africa. Elephant Pepper Development Trust, Livingstone, Zambia.

Poole, J.H. (1989) The effects of poaching on the age structures and social and reproductive patterns of selected East African elephant populations. In The Ivory Trade and the Future of the African Elephant, pp. 1-73. African Wildlife Foundation, Nairobi, Kenya.

Puyravaud, J.P., Davidar, P., Srivastiva, R.K. \& Wright, B. (2016) Modelling harvest of Asian elephants Elephas maximus on the basis of faulty assumptions promotes inappropriate management solutions. Oryx, http://dx.doi.org/10.1017/ Soo3060531600003X.

R Development Core Team (2014) R: A Language and Environment for Statistical Computing. R Foundation for Statistical Computing, Vienna, Austria.

Silver, S.C., Ostro, L.E.T., Marsh, L.K., Maffei, L., Noss, A.J., Kelly, M.J. et al. (2004) The use of camera traps for estimating jaguar Panthera onca abundance and density using capture/ recapture analysis. Oryx, 38, 148-154.

Sitati, N.W., Walpole, M.J., Smith, R.J. \& Leader-Williams, N. (2003) Predicting spatial aspects of human-elephant conflict. Journal of Applied Ecology, 40, 667-677.

Sмith, R.J. \& Kasiki, S.M. (2000) A Spatial Analysis of HumanElephant Conflict in the Tsavo Ecosystem, Kenya. IUCN, Gland, Switzerland.

SuKUMAR, R. \& GADGiL, M. (1988) Male-female differences in foraging on crops by Asian elephants. Animal Behaviour, 36, 1233-1235.
Thouless, C.R. (1994) Conflict between humans and elephants on private land in northern Kenya. Oryx, 28, 119-127.

Trivers, R.L. (1985) Social Evolution. Benjamin/Cummings Publishing, Menlo Park, USA.

Turkalo, A.K., Wrege, P.H. \& Wittemyer, G. (2013) Long-term monitoring of Dzanga Bai forest elephants: forest clearing use patterns. PLoS ONE, 8(12), e85154.

van Aarde, R.J. \& Jackson, T.P. (2007) Megaparks for metapopulations: addressing the causes of locally high elephant numbers in southern Africa. Biological Conservation, 134, 289-297.

Von Gerhardt, K., Van Niekerk, A., Kidd, M., Samways, M. \& Hanks, J. (2014) The role of elephant Loxodonta africana pathways as a spatial variable in crop-raiding location. Oryx, 48, 436-444.

Wallace, G.E. \& Hill, C.M. (2012) Crop damage by primates: quantifying the key parameters of crop-raiding events. PLoS ONE, 7 (10), e46636.

Wasser, S.K., Brown, L., Mailand, C., Mondol, S., Clark, W., LAURIE, C. \& WEIR, B.S. (2015) Genetic assignment of large seizures of elephant ivory reveals Africa's major poaching hotspots. Science, $349,84-87$.

Wilson, S., Davies, T.E., Hazarika, N. \& Zimmermann, A. (2015) Understanding spatial and temporal patterns of human-elephant conflict in Assam, India. Oryx, 49, 140-149.

Wittemyer, G., Northrup, J.M., Blanc, J.J., Douglas-Hamilton, I., Omondi, P. \& Burnham, L.P. (2014) Illegal killing for ivory drives global decline in African elephants. Proceedings of the National Academy of Sciences of the United States of America, 111, 13117-13121.

\section{Biographical sketches}

Josephine SMit works in elephant research and conservation in Tanzania and is interested in incorporating elephant behavioural ecology into conservation strategies. Rocí Pozo is a conservation biologist interested in human-wildlife conflict, with a particular focus on elephants, and the implications of wildlife management for local communities. JEREMY CUSACK is a conservation ecologist with an interest in the optimization of ecological monitoring methods. KATARZYNA NowAK is a wildlife conservation biologist who has studied primates and elephants in Tanzania and South Africa and is passionate about advancing ways by which people and wildlife can better coexist. She is currently a science and technology policy fellow at the American Association for the Advancement of Science. Trevor Jones has worked in wildlife research and conservation in Tanzania since 2002. His work focuses on training and empowering Tanzanians to effectively protect elephants and other wildlife for the long term. 